\title{
New OTA-C Current-mode Comb Filter
}

\author{
Dattaguru V. Kamath \\ Dept. of E\&C Engg., Manipal Institute of Technology, Manipal University, Manipal, India \\ E-mail:dv.kamath@manipal.edu, reachdvkamath@yahoo.com
}

\begin{abstract}
A new circuit realization for OTA-C current-mode comb filter is proposed to remove the undesirable multiple frequency signals. The proposed filter uses only OTAs and capacitors, hence suitable for monolithic integrated circuit implementation. The proposed OTA-C comb filter is simulated in PSPICE using a behavioral macro-model of the OTA as well with a practical CMOS OTA circuit. The workability of the comb filter is verified for hum signal frequencies of 60,180 and $300 \mathrm{~Hz}$ that are found in bio-medical signals. The results obtained are in good agreement with theory.
\end{abstract}

Keywords: Operational Transconductance Amplifier (OTA); Continuous-time (CT) or analog filter; Voltage-mode and current-mode filter; Single-Output OTA (SO-OTA); Dual-Output OTA (DO-OTA); CMOS OTA; Harmonic interference; Comb filter

\section{INTRODUCTION}

A number of biomedical instruments run on $\mathrm{AC}$ power line and hence suffer due to power line interference. The two components in power line interferences are electric field interference and magnetic field interference. The electrical field interference due to noise concentrated at the fundamental frequency generates spikes at $50 / 60 \mathrm{~Hz}$ frequency. The magnetic field associated with the transformer in the power supply section causes interference to generate harmonic frequencies of the fundamental. The power line interference degrades the quality of biomedical signals recorded which pose serious problems in correct interpretation of signals such as the electrocardiogram (ECG). The power line interference may be removed by both digital and analog filtering techniques [1]-[4]. The multiple notch or comb filter realization using op-amp and passive components is discussed in literature [2]-[3]. Recently, a voltage-mode OTA-C comb filter circuit is proposed [4].

Continuous-time (CT) or analog filters [5]-[25] are the most important analogue blocks in integrated signalprocessing systems. In the recent years, the use of continuous-time filters using active devices like opamp, operational transconductance amplifier (OTA) and current feedback operational amplifier (CFOA) has drawn more interest.

Operational transconductance amplifier (OTA) is a versatile analog building block used in voltage-mode and current-mode applications. It is widely used block in integrated circuit technique and suitable for various applications like continuous-time filters, oscillators. The OTA has an input differential pair and an output current mirror. The OTA is characterized by transconductance as the input of OTA is voltage and output is current. It has higher bandwidth and slew rate than op-amp. The transconductance of OTA can be controlled electronically by bias current over a wide range. The two advantageous features of OTA are the controllability of transconductance by changing the dc bias current and the ability to work at higher frequencies. Hence, most of the recently used continuous-time (CT) filter designs use devices other than op-amps such as OTAs. It is shown that the grounded and floating type resistors [6]-[11] can be simulated using OTAs. The grounded and floating inductances can be realized using OTAs and one grounded capacitor [2]-[7]. By replacing resistors and inductors with the simulated OTA circuits, the fully integrable and fully programmable active filters that use only OTAs and capacitors are realized. The OTA-C approach, where in only OTAs and capacitors are used, is shown to be useful for realizing voltage-mode [7]-[11], current-mode [8]-[21], [23], [24] and transimpedance-mode [22] filters. From last two decades, there is growing interest in Current-Mode Signal Processing (CMSP) [8] because of its advantages like increased band-width and reduced power supply requirements. The single output OTAs (SO-OTA) are popularly used for realizing voltage-mode filters. The dual output OTAs (DO-OTA) are employed to realize the current-mode active filters having current-input currentoutput (CICO) transfer functions.

In section II the synthesis of new OTA-C current-mode comb filter structure is presented. The PSPICE results obtained by simulating OTA-C comb filter circuit using a behavioral macro-model of the OTA as well with a practical CMOS OTA circuit are presented in section III. The concluding remarks are given in section IV.

\section{PROPOSED OTA-C CURRENT-MODE COMB FILTER}

The symbolic representation of single output OTA (SOOTA) and dual output OTA (DO-OTA) used in this work are shown in Fig. 1(a) and (b) respectively. The two current outputs of DO-OTA are given by

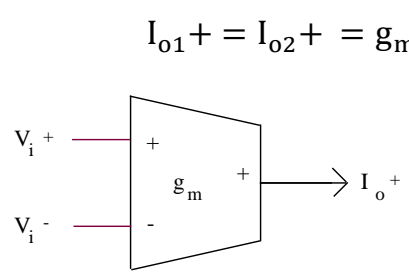

(a)
Fig. 1 Circuit symbol of (a) SO-OTA (b) DO-OTA 
Here, $\mathrm{I}_{\mathrm{o} 1}{ }^{+}, \mathrm{I}_{\mathrm{o} 2}{ }^{-}$are the two output source currents, $\mathrm{V}_{\mathrm{i}}^{+}$ and $\mathrm{V}_{\mathrm{i}}^{-}$denote non-inverting and inverting input voltages of the DO-OTA respectively.

The proposed OTA based current-in current-out (CICO) one admittance circuit configuration with only one input current is shown in Fig. 2, the transfer function of which is shown to be

$$
\frac{I_{o}}{I_{\text {in }}}=\frac{g_{m}}{\left(g_{m}+Y\right)}
$$

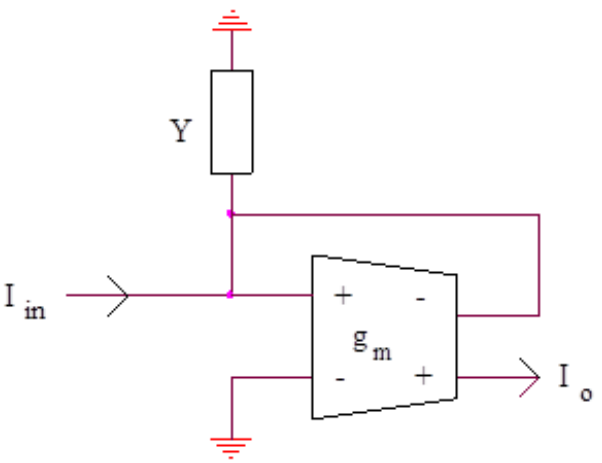

(a)

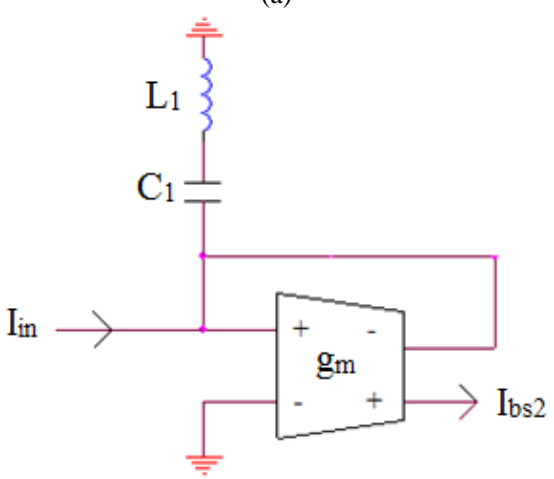

(b)

Fig. 2 (a) DO-OTA based single admittance circuit configuration with only one input current, (b) OTA-C current-mode band-stop biquad realized from circuit in Fig. 1(a)

It can be shown that a current-mode band-stop biquad (refer Fig. 2(b)) can be realized from DO-OTA based single admittance circuit configuration of Fig. 2(a) by selecting $\mathrm{Y}$ as capacitor $\mathrm{C}_{1}$ in series with grounded inductor $\mathrm{L}_{1}$. The transfer function of current-mode biquad in Fig. 2(b) is shown to be

$$
\frac{\mathrm{I}_{\mathrm{bs} 2}}{\mathrm{I}_{\mathrm{in}}}=\frac{\mathrm{g}_{\mathrm{m}}}{\left(\mathrm{g}_{\mathrm{m}}+\frac{\mathrm{s} C_{1}}{\mathrm{~s}^{2} L_{1} C_{1}+1}\right)}
$$

From (1.2b), the expression for pole frequency, pole- $\mathrm{Q}$ and bandwidth $\Delta \mathrm{f}$ of notch filter are shown to be

$$
\omega_{\mathrm{o}}=\frac{1}{\sqrt{\mathrm{L}_{1} \mathrm{C}_{1}}}
$$

$$
\begin{gathered}
\mathrm{Q}_{\mathrm{o}}=\mathrm{g}_{\mathrm{m} 1} \sqrt{\frac{\mathrm{L}_{1}}{\mathrm{C}_{1}}} \\
\Delta \mathrm{f}=\frac{1}{\mathrm{~g}_{\mathrm{m} 1} \mathrm{~L}_{1}}
\end{gathered}
$$

From $(1.2 \mathrm{c})$ it is evident that pole- $\mathrm{Q}$ can be independently tuned without need to change pole frequency.

The sensitivity of pole-frequency and pole-Q with respect to component values are shown to be

$$
\begin{gathered}
\mathrm{S}_{\mathrm{L}_{1}}^{\omega_{\mathrm{o}}}=\mathrm{S}_{\mathrm{C}_{1}}^{\omega_{\mathrm{o}}}=-0.5 \\
\mathrm{~S}_{\mathrm{L}_{1}}^{\mathrm{Q}_{\mathrm{o}}}=-\mathrm{S}_{\mathrm{C}_{1}}^{\mathrm{Q}_{\mathrm{o}}}=0.5 ; \mathrm{S}_{\mathrm{g}_{1}}^{\mathrm{Q}_{\mathrm{o}}}=1
\end{gathered}
$$

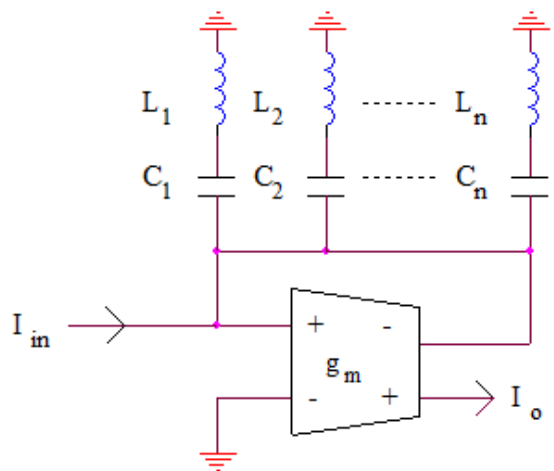

Fig. 3 Generalized active comb filter using a DO-OTA and L-C series sections

By routine analysis of the circuit in Fig. 3, the currentmode transfer function of the active comb filter is shown to be

$$
\mathrm{T}(\mathrm{s})=\frac{\mathrm{I}_{\mathrm{o}}}{\mathrm{I}_{\mathrm{in}}}=\frac{\mathrm{g}_{\mathrm{m}}}{\left(\mathrm{g}_{\mathrm{m}}+\sum_{\mathrm{i}=1}^{\mathrm{n}} \frac{\mathrm{s \textrm {C } _ { \mathrm { i } }}}{\mathrm{s}^{2} \mathrm{~L}_{\mathrm{i}} \mathrm{C}_{\mathrm{i}}+1}\right)}
$$

The $\mathrm{i}^{\text {th }}$ notch filter is used to eliminate the $\mathrm{i}^{\text {th }}$ harmonic component from the input signal $V_{\text {in }}(t)$. The transfer function of the $\mathrm{n}^{\text {th }}$ notch filter is obtained as

$$
\mathrm{T}^{\mathrm{n}}(\mathrm{s})=\frac{\mathrm{s}^{2} \mathrm{~L}_{\mathrm{n}} \mathrm{C}_{\mathrm{n}}+1}{\mathrm{~s}^{2} \mathrm{~L}_{\mathrm{n}} \mathrm{C}_{\mathrm{n}}+\mathrm{s} \frac{\mathrm{C}_{\mathrm{n}}}{\mathrm{gm}_{\mathrm{m}}}+1}
$$

The generalized $[\mathrm{n}=3$ in (1.3a)] circuit of OTA-C current-mode notch filter using all OTAs and capacitors is shown in Fig. 4. The inductance $L_{n}$ in Fig. 4 is expressed as

$$
L_{n}=\frac{C_{L n}}{g_{n A} g_{n B}}
$$

where $g_{n A}$ and $g_{n B}$ are the transconductances of the OTAs. 


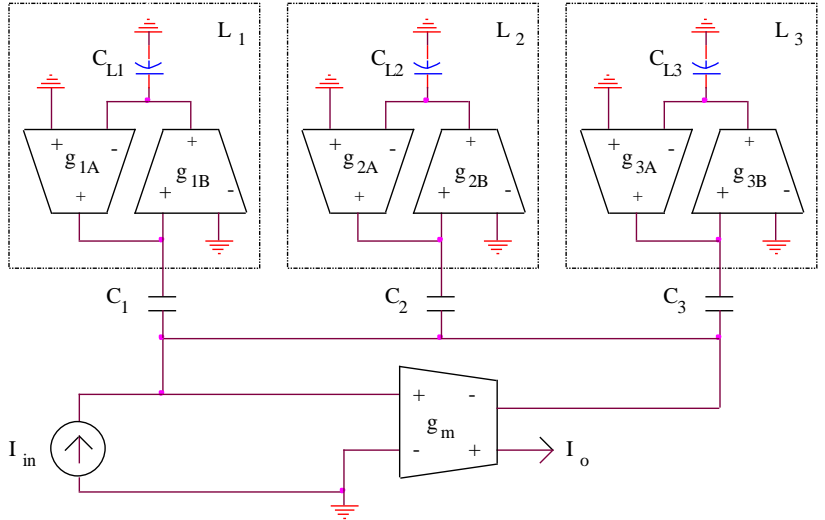

Fig. 4 Generalized $[\mathrm{n}=3$ in $(1.1 \mathrm{e})]$ circuit arrangement for implementing OTA-C current-mode comb filter

The proposed generalized OTA-C comb filter in Fig. 4 can eliminate $n$ number of undesirable frequencies. The transfer function of the $\mathrm{n}^{\text {th }}$ band-stop or notch filter in generalized OTA-C comb filter of Fig. 4 is shown to be

$$
T^{n}(s)=\frac{s^{2}+\frac{g_{n A} g_{n B}}{C_{L n} \cdot C_{n}}}{s^{2}+s \frac{g_{n A} g_{n B}}{g_{m} C_{L n}}+\frac{g_{n A} g_{n B}}{C_{L n} C_{n}}}
$$

The expressions for the characteristic parameters of $n^{\text {th }}$ notch filter are modified as shown below:

$$
\begin{gathered}
\omega_{\text {on }}=\sqrt{\frac{g_{n A} g_{n B}}{C_{L n} C_{n}}} \\
Q_{o n}=g_{m 1} \sqrt{\frac{C_{L n}}{g_{n A} g_{n B} C_{n}}} \\
\Delta \mathrm{f}_{n}=\frac{g_{n A} g_{n B}}{g_{m 1} C_{L n}}
\end{gathered}
$$

\section{SIMULATION RESULTS}

The proposed generalized $[\mathrm{n}=3$ in (1.1e)] OTA-C current-mode comb filter in Fig. 4 have been simulated using PSPICE simulator using the design details given in Table I. The comb filter is simulated using behavioral voltage controlled current source (VCCS) model of OTA (i.e., ideal transconductor with infinite $R_{o}$ and zero $C_{o}$ as shown in Fig. 5(a)) to obtain the ideal characteristics.

TABLE I SIMULATION DETAILS

\begin{tabular}{|c|c|}
\hline Model parameters used & Level $30.5 \mu \mathrm{m}$ MOSIS \\
\cline { 1 - 1 } Device dimension for NMOS transistors & \multirow{2}{*}{$\begin{array}{l}\mathrm{W}=4 \mu \mathrm{m}, \\
\mathrm{L}=2 \mu \mathrm{m}\end{array}$} \\
\cline { 1 - 1 } Device dimension for PMOS transistors & \\
\hline Supply voltages & $\mathrm{V}_{\mathrm{dd}}=+5 \mathrm{~V}, \mathrm{~V}_{\mathrm{ss}}=-5 \mathrm{~V}$ \\
\hline
\end{tabular}

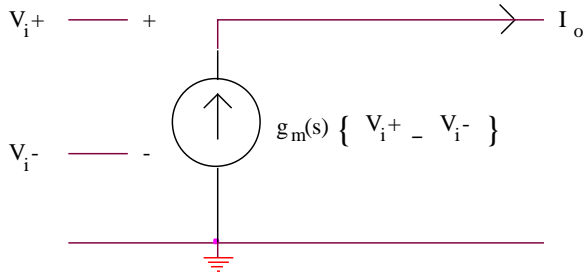

(a)

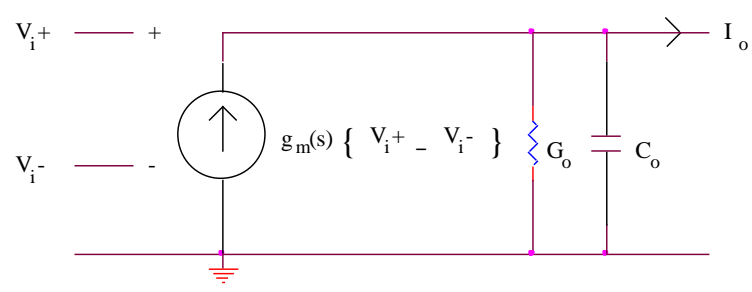

(b)

Fig. 5 (a) Ideal VCCS and (b) Non-ideal model of SO-OTA

As proposed active comb filter is intended for biomedical signals of low-frequency range, a low noise and low distortion OTA suitable for low-frequency application [25] is used. The schematic circuits of CMOS cascode SOOTA and DO-OTA analog blocks used in our work are shown in Fig. 6 and Fig. 7 respectively.

The OTA-C current-mode comb filter in Fig. 4 has been simulated using $\mathrm{g}_{\mathrm{m}}=\mathrm{g}_{1 \mathrm{~A}, \mathrm{~B}}=\mathrm{g}_{2 \mathrm{~A}, \mathrm{~B}}=\mathrm{g}_{3 \mathrm{~A}, \mathrm{~B}}=$ $59.2 \mathrm{nS} \quad\left(\mathrm{I}_{\text {bias }}=5 \mathrm{nA}\right), \mathrm{C}_{1}=\mathrm{C}_{\mathrm{L} 1}=157.033 \mathrm{pF}, \mathrm{C}_{2}=$ $\mathrm{C}_{\mathrm{L} 2}=52.344 \mathrm{pF}, \mathrm{C}_{3}=\mathrm{C}_{\mathrm{L} 3}=31.407 \mathrm{pF}$ designed to eliminate power line interference signals of fundamental frequency of $60 \mathrm{~Hz}$ and its odd harmonics 180, $300 \mathrm{~Hz}$. The resulting amplitude responses obtained using behavioral macro model of OTA and practical CMOS OTA circuit [4], [25] are shown respectively in Fig. 8 (a)(b).

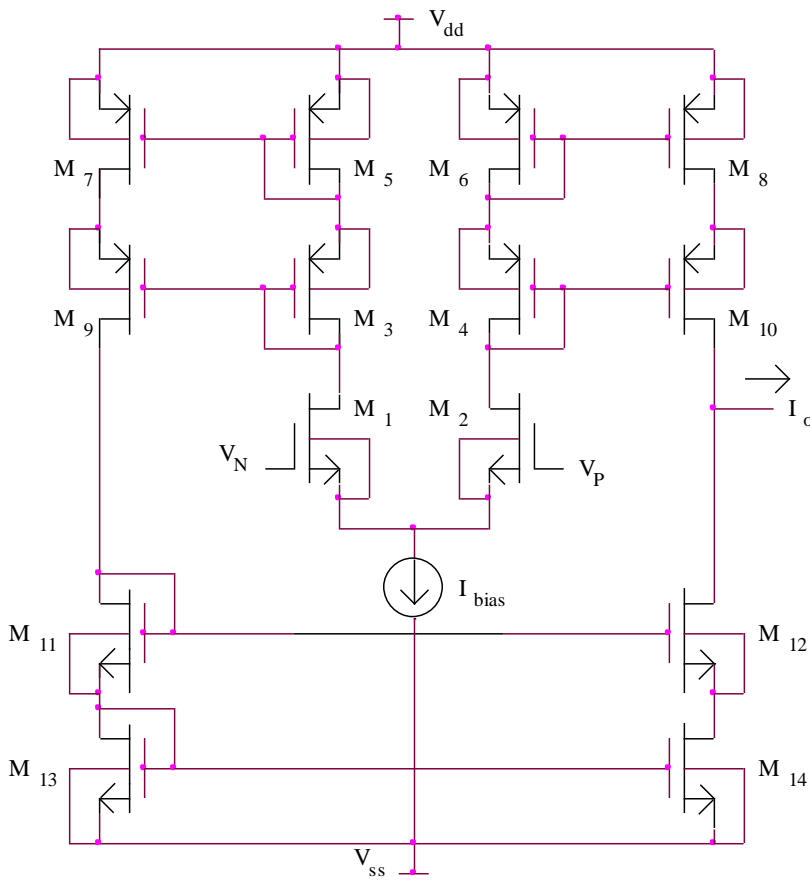

Fig. 6 CMOS schematic circuit of cascode SO-OTA 




Fig. 7 CMOS schematic circuit of cascode DO-OTA

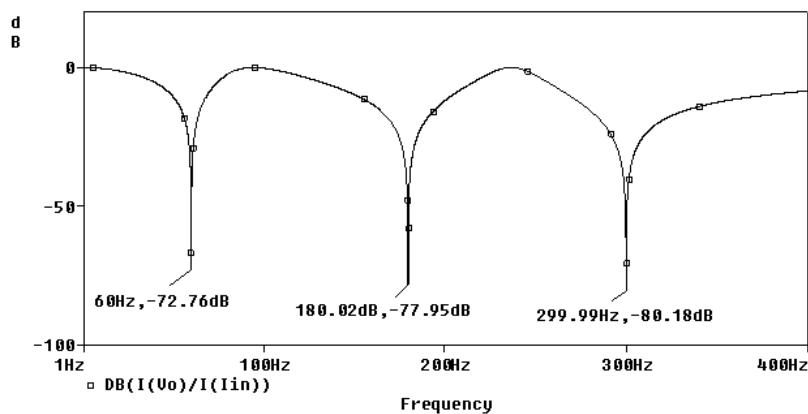

(a)



(b)

Fig. 8 Amplitude responses of OTA-C current-mode comb filter in Fig. 4 obtained using (a) a behavioral OTA macro model (b) a low frequency low noise CMOS OTA [25]

From the plots presented in Fig. 8 (a)-(b) it is evident that the simulation results are in good agreement with theory.

\section{CONCLUSION}

In this paper, the circuit realization of generalized active comb filter using only OTAs and capacitors is discussed. The workability of the comb filter for removal of undesired power line signals of fundamental frequency of $60 \mathrm{~Hz}$ and its odd harmonics $180,300 \mathrm{~Hz}$ has been tested using behavioral model of OTA as well with a practical low frequency OTA by using PSPICE. The simulated and theoretical results agreed quite well.

\section{REFERENCES}

[1] Neelam Mehala, Anand, "IIR Multiple Notch Filter Design for Power Line Interference Removal," International Journal of Emerging Science and Engineering (IJESE), vol.1, no. 10, August 2013.

[2] Chang-Tar Tsai, Hsiao-Lung Chan, Chien-Chen Tseng and ChienPing Wu, "Harmonic Interference Elimination by An Active Comb Filter," Proceedings of 16th Annual International Conference of IEEE Engineering in Medicine and Biology Society, vol.2, pp. 964 965, Baltimore, Md, USA, November 1994.

[3] Chang-Da Tsai, Dah-Chuan Chiou, Yue-Der Lin, Hsiao-Lung Chan, and Chien-Ping $\mathrm{Wu}$, "An active comb filter design for harmonic interference removal," Journal of the Chinese Institute of Engineers, vol. 21, no. 5, pp. 605-610, 1998.

[4] Rajeev Kumar Ranjan, Surya Prasanna Yalla, Shubham Sorya, and Sajal K. Paul, "Active Comb Filter Using Operational Transconductance Amplifier," Active and Passive Electronic Components, Volume 2014, Article ID 587932, 6 pages.

[5] S. Sedra and P. O. Brackett, Filter Theory and Design: Active and Passive, Matrix Series in Circuits and Systems, Matrix Publishers, 1978.

[6] R. Schaumann, M. S. Ghausi, K. R. Laker, Design of analog filters: passive, active RC and switched capacitor, Prentice-Hall, Englewood cliffs, New Jersey, 1981.

[7] R. L. Geiger and E. Sanchez-Sinencio, "Active filter design using operational transconductance amplifiers: a tutorial," IEEE Circuit and Devices Magazine, vol. 1, pp. 20-32, 1985.

[8] Toumazou, F. D. Lidgey, and D. G. Haigh, Analog IC Design: The Current Mode Approach. London, U.K.: Peregrinus, 1990.

[9] T. Deliyannis, Y. Sun, and J. K. Fidler, Continuous-Time Active Filter Design, CRC Press, Florida, U.S.A, 1999

[10]P. V. Ananda Mohan, Current-Mode VLSI Analog Filters: Design and Applications, Birkhäuser Boston, 2003.

[11]P. V. Ananda Mohan, VLSI Analog Filters: Active RC, OTA-C, and SC, Birkhäuser Boston, 2013.

[12] M. Al-Hashimi, "Current mode filter structure based on dual output transconductance amplifiers," Electronics Letters, vol. 32, pp. 25-26, 1996.

[13] Dattaguru V. Kamat, P. V. Ananda Mohan and K. Gopalakrishna Prabhu, "Novel First-order and Second-Order Current-mode filters using dual-output OTAs and Grounded Capacitors," IEEE Asia Pacific Region 10 (TENCON) Conference held at Hyderabad, India, IEEExplorer, pp. 1-6, 19-21Nov. 2008

[14] Dattaguru V. Kamath, P. V. Anandamohan and K. Gopalkrishna Prabhu, "Novel first order and second order current-mode filters using multiple output operational transconsuctance amplifiers," Circuits, Systems, and Signal Processing, Birkhäuser Boston Publishers, vol. 29, no. 3, pp. 553-576, June 2010.

[15] Dattaguru V. Kamat, P. V. Ananda Mohan and K. Gopalakrishna Prabhu, "Current-mode operational transconductance amplifiercapacitor biquad filter structures based on Tarmy-Ghausi Active-RC filter and second-order digital all-pass filters," IET Circuits, Devices and Systems, vol. 4, no. 4, pp. 346-364, July 2010.

[16] Dattaguru V. Kamat, P. V. Ananda Mohan and K. Gopalakrishna Prabhu, "Active-RC filters using two-stage OTAs with and without feed-forward compensation," IET Circuits, Devices and Systems, vol. 5, no. 6, pp. 527-535, Nov 2011.

[17] Dattaguru. V. Kamath P. V. Ananda Mohan, Gopalakrishna Prabhu K, "OTA-based current-mode filter and oscillator," US Patent, No. US 8,659,363 B2, Feb 2014

[18] Dattaguru V. Kamath, "New OTA-C Current-Mode Second-Order Filters," IIE International Conference on Innovative Engineering Technologies (ICIET 2014) held at Bangkok, Thailand, pp. 137-143, 28-29 Dec. 2014.

[19] Dattaguru V. Kamath, "TO-OTA based current-mode biquad filters," Transactions on Engineering and Sciences, vol. 2, no. 8, pp. 15-26, August 2014.

[20] Dattaguru V. Kamath, "Novel OTA-C Current-Mode Third-Order Band-Pass Filters," International Journal of Innovative Research in Electrical, Electronics, Instrumentation and Control Engineering (IJIREEICE), vol. 2, no. 8, pp. 1861 - 1865, August 2014. 
[21] Dattaguru. V. Kamath, "New OTA-C Current-Mode Second-order Manipal Institute of Technology, Manipal University, Manipal, and Fourth-Order Band-Pass Filters," International Journal of Innovative Research in Electrical, Electronics, Instrumentation and Control Engineering (IJIREEICE), vol. 3, no. 6, pp. 130-134, June 2015.

[22] Dattaguru. V. Kamath, "OTA-C Transimpedance Biquads derived from Passive Filters," International Journal of Technical Research and Applications (IJTRA), Special Issue 23, pp. 6-12, June, 2015.

[23] Dattaguru V. Kamath, "Overview of Opamp and OTA based Integrators," International Journal of Innovative Research in Electrical, Electronics, Instrumentation and Control Engineering (IJIREEICE), vol. 3, no. 9, pp. 74-81, Sept. 2015.

[24] T. Tsukutani, Y. Sumi, and Y. Fukui, "Electronically tunable current-mode OTA-C biquad using two-integrator loop structure," Frequenz, vol. 60, pp. 53-56, 2006.

[25] G. Duzenlia, Y. Kcili, H. Kuntmanc, and A. Atamanb, "On the design of low-frequency filters using CMOS OTAs operating in the subthreshold region," Microelectronics Journal, vol. 30, no. 1, pp. 45-54, 1999.

\section{BIOGRAPHY}



Dr. D. V. Kamath obtained $\mathrm{PhD}$ in the field of Analog VLSI Signal Processing from Manipal University (MU), Manipal, India in the year 2013. He obtained B.E (Electronics and Communication) and M.E (Digital electronics) from B. V. Bhoomreddi College of Engineering and Technology, Karnataka University, Dharwad (KUD) in the year1987

and 1997 respectively. Currently working as Professor in the Department of Electronics and Communication Engineering,

India. The research and academic contribution includes grant of one US patent, 25 full regular papers published in indexed international journals of good repute, 5 indexed international conference publications. Author's areas of research interest include Digital, Analog and Mixed Signal VLSI design and Analog VLSI Signal Processing

He has presented/ conducted key-note address/ tutorials and seminars at various International/ National Level Conferences/ Workshops. Author's Biography/ Profile is published in the 2011-2012 (11th) Edition of Marquis Who's Who in Science and Engineering and 2014 (31st) and 2015 (32 $\left.{ }^{\text {nd }}\right)$ Edition of Marquis Who's Who in the World, the world-renowned reference directories. He is working as Editor of Transactions on Engineering and Sciences (TES) Journal and Advisory Board Member of International Journal of Innovative Research in Electrical, Electronics, Instrumentation and Control Engineering (IJIREEICE), International Journal of Advanced Research in Computer and Communication Engineering (IJARCCE), Journal of Global Research in Electronics and Communication (JGREC). $\mathrm{He}$ is currently working as Reviewer for Adavances in Signal Processing Journal. He has reviewed research papers for various international/ national level conferences. 